\title{
Genotipagem de Papiloma Vírus H umano em paciente com papilomatose laríngea recorrente
}

\author{
Genotyping of Human Papillomavirus in patient with recurrent laryngeal \\ papilomatose
}

Antonio Márcio Teodoro Cordeiro Silva, ${ }^{1}$ Aparecido Divino da Cruzz, ${ }^{1,23}$ Cláudio Carlos da Silva, ${ }^{1}$ Fabiano Ribeiro Borges ${ }^{1}$ e Maria Paula Curado ${ }^{2}$

\section{Resumo}

O s H PV s são vírus de D N A circular de fita dupla medindo cerca de $8000 \mathrm{pb}$. Vários estudos têm demonstrado que o H PV é o agente causal de tumores benignos, como papilomas, verrugas comuns e condilomas. Com 0 avanço das técnicas de detecção molecular, o genoma do H PV tem sido freqüentemente identificado em células neoplásicas malignas de origem epitelial, passando-se a associar o H PV a alguns tumores epiteliais, principalmente ao carcinoma cervical. Recentemente, diversas pesquisas se concentraram na tentativa de associar a infecção por H PV s aos cânceres de cabeça e pescoço. 0 presente relato de caso consiste na avaliação de uma paciente com história de papilomatose recorrente na laringe. U ma criança com sete anos de idade, do sexo feminino, foi atendida há dois anos com queixas de desconforto na garganta e disfonia. 0 s vários procedimentos clínicos indicaram presença de papilomas na laringe e o histopatológico acusou presença de coilocitose, achado sugestivo da infecção por H PV. Assim, a paciente foi submetida à retirada cirúrgica dos papilomas. Das peças cirúrgicas foi obtido D N A total, usado na investigação molecular, por PCR, para detecção do genoma de H PV. D esta forma, foi confirmada a presença do H PV do tipo 11, corroborando os achados de outros autores que argumentam que a ocorrência latente do H PV 11 tem participação na evolução dessa patologia em crianças.

Palavras-chave: papiloma; neoplasias laríngeas; papillomavirus humano; reação em cadeia por polimerase; D N A; HPV.

${ }^{1}$ úcleo de Pesquisas Replicon, D epartamento de Biologia, Universidade Católica de Goiás, Goiânia,GO .

${ }^{2}$ Registro de Câncer de Base Populacional, Associação de Combate ao Câncer em Goiás, G oiânia, GO .

${ }^{3}$ LaG ene - Laboratório de Citogenética Humana e Genética M olecular, SuLeide/SES-GO, Goiânia, GO. Enviar correspondência para M.P.C.

E-mail: acruz@ucg.br 


\begin{abstract}
H PV is a circular doublestand D N A virus with approximately $8000 \mathrm{bp}$. Some studies have implicated H PV as the etiological agent of benign tumors such as papilomas, commons warts, and condilomas. W ith the advance of molecular techniques, detection of the H PV genome has been made fairly easy and has been frequently identified in malign neoplasic cells of epithelial origin, associating the HPV with some epithelials tumors, mainly with cervical carcinoma. Recently, several studies have been aiming to understand the role H PV infection in the initiation and promotion of head and neck cancers. The following article consists of a case report of a patient with history of respiratory recurrent papillomatosis. A 7-year old female patient was examined upon complaint of discomfort and pain in her throat, including disphonic episodes. Common clinical procedures indicated the presence of papilomas in her larynx. The histopathological analysis of the papilomas revealed coilocytosis, suggesting H PV infection. The patient underwent a polypectomy and the tissue was used to extract total D N A for the molecular investigation of the HPV genome by PCR. The results confirmed the presence of HPV11, corroborating findings reported elsewhere that implicated H PV 11 as a participant in the evolution of benign recurrent respiratory papillomatosis in children.
\end{abstract}

Key words papilloma; laryngeal neoplasms; human papillomavirus; polymerase chain reaction; D N A; H PV.

\section{INTRO DUÇÃO}

\section{PAPILOMA VÍRUS HUMANO (HPV)}

O s H PV s são vírus da família Papovaviridae, que formam partículas virais icosaédricas sem envelope, com cerca de 55nm de diâmetro. A presentam um D N A circular de fita dupla, medindo de 7500 a 8000pb (Figura 1). Atualmente, são conhecidos mais de 100 tipos de H PV s. Espera-se que os estudos de tipagem de H PVs associados aos cânceres de cabeça e pescoço possam aumentar ainda mais este número. ${ }^{1-5}$

O HPV é considerado o agente causal de tumores benignos como papilomas, verrugas comuns e condilomas. Com 0 avanço das técnicas de detecção molecular, o genoma do H PV tem sido identificado em células neoplásicas malignas. Assim, o HPV passou a ser associado a cânceres, principalmente com o carcinoma cervical. As evidências da associação destes vírus com neoplasias somadas a estudos epidemiológicos publicados recentemente permitiram estabelecer uma relação etiológica entre alguns tipos de H PV s e o carcinoma cervical. ${ }^{6-8}$

O H PV infecta células epiteliais mucosas e cutâneas do tecido epitelial pavimentoso estratificado e produz vírions na medida que estas células se diferenciam. Por isso o ciclo de vida do HPV é denominado ciclo viral dependente da diferenciação. A infecção inicial por H PV ocorre, provavelmente, em células epiteliais tronco ou basais ou em células que estão transitoriamente se dividindo, localizadas nas camadas mais baixas do epitélio estratificado. À medida que as células mais profundas do epitélio vão se dividindo elas migram da camada basal e se tornam gradativamente diferenciadas ${ }^{9}$ (Figura 2).

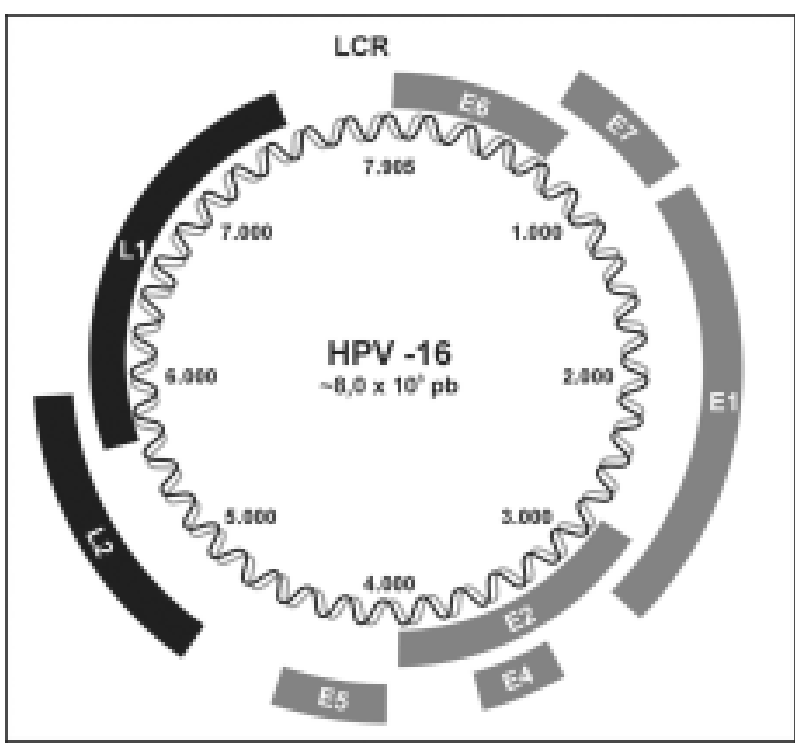

Figura 1: Mapa genético do papiloma vírus humano 16 (HPV16). $G$ enoma circular de dupla-fita, mostrando organização e localização dos genes. LCR: Longa Região de Controle.

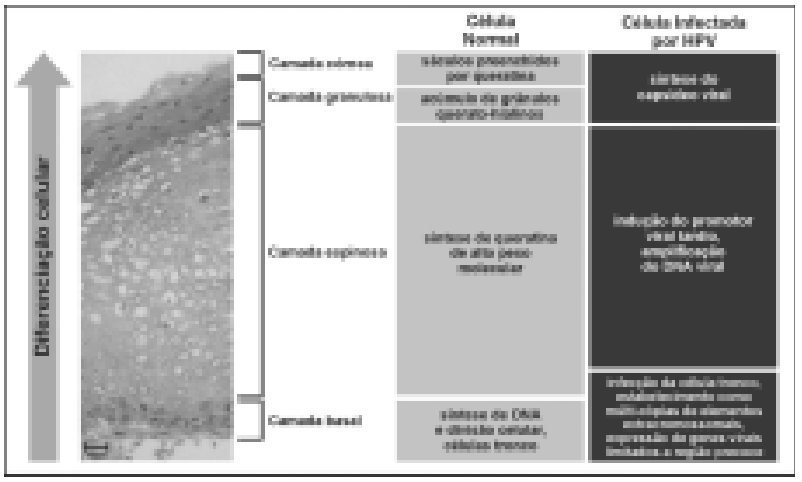

Figura 2: Fotomicrografia de tecido epitelial da laringe mostrando o ciclo viral dependente da diferenciação para células normais e infectadas por HPV. 
Assim que o H PV infecta a célula, os genomas do vírus são mantidos como elementos extracromossômicos estáveis nos núcleos. Em seguida, as cópias do genoma viral são replicadas até o número de 50 a 100 cópias por célula. Q uando as células infectadas se dividem acontece uma distribuição equivalente de genomas virais entre as células filhas. A divisão das células tronco tem duas finalidades: oferecer células para a diferenciação, que migrarão para a superfície do epitélio e manter as células indiferenciadas da camada basal. Assim, estas células funcionam como um reservatório do genoma viral. ${ }^{10}$

A estratégia da infecção pelo H PV envolve as células da camada basal, mas a produção de vírions é restrita à camada suprabasal, ou seja, a camada mais diferenciada. Essa diferenciação dependente é uma estratégia do vírus, pois promove a infecção através da produção de vírions nas células maduras e garante a manutenção persistente do H PV nas camadas basais por períodos de até vários anos. ${ }^{9,10}$

\section{CLASSIFICAÇÃOO DOS HPVS}

Existem duas classificações para os H PV s. A primeira está relacionada com o tropismo do vírus pelo tipo de epitélio; que são de duas classes distintas: (1) cutaneotrópicos, tipos virais capazes de infectar a epiderme; e (2) mucosotrópicos, tipos virais capazes de infectar mucosas em geral. A segunda divide os H PVs em duas categorias de risco para o desenvolvimento de neoplasias: (1) baixo risco e (2) alto risco oncogênico (Tabela 1). ${ }^{8}$ O s vírus considerados de baixo risco estão associados mais comumente a lesões benignas, como papilomas e verrugas simples, principalmente condilomas. Já os vírus considerados de alto risco estão associados a diferentes graus de lesões escamosas intraepiteliais do colo do útero, vagina, vulva, pênis, ${ }^{11,12}$ dos carcinomas cervicai $s^{6,7}$ e de carcinomas de cabeça e pescoço, como por exemplo, os sítios anatômicos da cavidade oral, orofaringe, hipofaringe e laringe. ${ }^{13-19}$

Tabela 1. Classificação dos HPVs quanto ao risco oncogênico, incluindo a natureza das lesões virais mais freqüentemente associadas.

\begin{tabular}{|c|c|c|}
\hline Classificação & Tipo Viral & Lesão \\
\hline Baixo risco & $6,11,26,42,44,54,70$ e 73 & Benigna \\
\hline Alto risco & $\begin{array}{l}16,18,31,33,35,39,45, \\
51,55,56,58,59,66 \text { e } 68\end{array}$ & Maligna \\
\hline
\end{tabular}

INTERAÇÃO MOLECULAR ENTRE O VÍRUS E A CÉLULA

0 gene supressor de tumor RB1 está localizado no cromossomo 13q14, cujo produto é a proteína celular $\mathrm{pRb}$. A pRb está associada à inibição da progressão do ciclo celular, pois é capaz de seqüestrar o fator de transcrição E2F e impedi-lo de promover a transcrição de genes necessários para a replicação do D N A na fase S. Assim, a pRb exerce uma regulação negativa do ciclo celular através da sua fosforilação específica ciclodependente. U ma vez fosforilada, a ligação entre pR b e E2F não acontece, resultando no estímulo da transcrição dos genes responsáveis pela replicação dos cromossomos durante a fase $S$ do ciclo celular. A associação da proteína pRb com a proteína viral E7 causará uma perturbação no controle normal do ciclo celular, resultando em um estímulo excessivo para a proliferação das células infectadas. ${ }^{20-24}$

A proteína E7 de H PV s de alto risco está associada à inativação das proteínas da família pRb. A proteína viral E7 é reconhecidamente eficiente na formação de complexos com ciclinas A e E. No entanto, estudos recentes sugerem essa mesma eficiência quando $E 7$ forma complexos estáveis com as proteínas pRb. Com a inativação da proteína $\mathrm{pRb} 0$ fator de transcrição E2F não pode ser reprimido, em conseqüência, a célula perde o controle do ciclo celular. ${ }^{2,9,25}$

0 gene supressor de tumor p53 está localizado no cromossomo 17p13, cujo produto é a proteína p53. U ma vez ativada, a proteína p53 é capaz de reprimir o crescimento e sinalizar para a morte celular, rota metabólica denominada apoptose. A proténa p53 tem a habilidade em perceber diferentes tipos de estresses que podem acometer as células, com conseqüentes danos ao D N A. A ativação da proteína p53 após estresse celular é capaz de mobilizar uma defesa na qual a própria p53 age ativando outros genes capazes de codificar proteínas necessárias para esse processo de defesa, como por exemplo, os genes do mecanismo de reparo. N este contexto, a proteína p53 é responsável por monitorar danos ocorridos nas biomoléculas de D N A. D esta forma o ciclo celular é impedido de prosseguir até que o dano no DNA seja restaurado. ${ }^{26,27}$

A proteína $\mathrm{E} 6$ de H PVs de alto risco é capaz de se associar à proteína p53, que é responsável pela regulação da passagem da fase $G 1$ para $S$ e da fase $G 2$ para $M$, no ciclo celular. A proteína viral $\mathrm{E} 6$ recruta a proteína celular E6AP, que funciona como uma ubiquitina-ligase para 0 complexo contendo p53. Este recrutamento resulta na ubiquitinação de p53 seguido de sua rápida degradação. ${ }^{7}$ Sem a proteína p53 a célula perde a capacidade de perceber e reparar possíveis danos no D N A, assim a divisão celular passa a ocorrer sem reparo. Conseqüentemente, aumenta-se a freqüência das mutações, dos rearranjos cromossômicos e das aneuploidias. 0 acúmulo de eventos mutacionais é a causa subjacente ao desenvolvimento de um fenótipo neoplásico e, assim, provavelmente, resultam no câncer. ${ }^{9,28-31}$ 
PAPILOMATOSE LARÍNGEA

A infecção genital por H PV é de transmissão sexual, evolvendo tanto os HPVs de baixo risco quanto os de alto risco para o desenvolvimento de neoplasias. Os H PV s 6 e 11 são mais comumente encontrados em condilomas genitais, e os tipos 16, 18, 31 e 45 em carcinoma cervical. Estes últimos perfazem mais de $80 \%$ dos tipos detectados nos carcinomas cervicais. A manifestação clínica mais importante da infecção da laringe por H PV é o papiloma laríngeo, que é enquadrado na categoria das papilomatoses respiratórias recorrentes. Atualmente, esta enfermidade é dividida em dois grupos distintos: (1) papiloma laríngeo de início juvenil e(2) papiloma laríngeo de início na idadeadulta. ${ }^{10}$

O s papilomas laríngeos de início juvenil são associadas aos H PV s transmitidos por via vertical de uma mãe com infecção anogenital ativa ou latente. $M$ ais de $30 \%$ de mães com condilomas genitais deram à luz a crianças que desenvolveram papilomatose laríngea de início juvenil. ${ }^{32}$ Essa doença ocorre mais comumente em crianças do primeiro nascimento e por parto normal de mães jovens com condiloma genital. O s casos de crianças com papilomatose laríngea que nasceram por cesariana são raros. Estes H PV s estimulam a proliferação de papilomas nas vias aéreas, preferencialmente, na laringe. A progressão dos papilomas é lenta, gerando uma sintomatologia progressiva de dificuldade respiratória, disfonia e tosse persistente. ${ }^{32,33}$

A papilomatose laríngea juvenil acomete igualmente ambos os sexos e o fator mais preocupante é disseminação do vírus pela árvore traqueobronqueal, evoluindo para a papilomatose pulmonar, muita vezes resultando em uma infecção incontrolável e fatal. 0 utro evento importante é a transformação maligna dos papilomas laríngeos que apesar de ser um evento raro, ocorre em cerca de 3 a $7 \%$ dos casos. ${ }^{10}$

0 tratamento é baseado na remoção cirúrgica dos pólipos por laser de $\mathrm{CO}_{2}$, que é o método de escolha, criado no início da década de 70. A cirurgia convencional está longe de ser a melhor categoria de tratamento, devido à etiologia viral da doença. 0 a-Interferon, às vezes, é administrado, especialmente para crianças, porque nestes casos em particular, a papilomatose laríngea é mais agressiva que nos casos adultos, com recidivas freqüentes e possibilidade da migração do vírus para as partes baixas do trato respiratório. 0 objetivo do tratamento é manter as vias aéreas livres e a qualidade da voz. ${ }^{10}$

Os papilomas laríngeos de início na idade adulta acometem indivíduos com maior número de parceiros sexuais e maior freqüência de contatos orogenitais. A hipótese de transmissão orogenital é baseada no fato de que a papilomatose da laringe e os condilomas genitais apresentam os mesmos H PV s das infecções associadas, H PVs 6 e 11, sendo o tipo 6 o mais freqüente. A área de transição de epitélios cubóide e cilíndrico na laringe e na cérvice uterina pode favorecer a ocorrência do H PV neste local e a semelhança entre essas regiões parece favorecer, preferencialmente, a infecção do epitélio da laringe sobre 0 epitélio bucal. ${ }^{10,33,34}$

0 presente estudo foi realizado objetivando a genotipagem molecular de H PV em um caso de papilomatose laríngea recorrente de uma paciente com sete anos de idade, com a finalidade de otimizar 0 tratamento e, conseqüentemente, auxiliar no prognóstico individual desse tipo particular de patologia.

\section{RELATO DE CASO}

Paciente do sexo feminino, com sete anos de idade, foi atendida há dois anos com queixas de desconforto na garganta e disfonia. 0 corpo clínico constatou presença de hipertrofia amigdaliana bilateral com obstrução parcial do óstio da laringe, sem linfadenopatia. A paciente foi submetida a oroscopia, confirmando-se amigdalite de grau III e hipertrofia da amígdala e adenóide. A videolaringoscopia sugeriu papilomatose laríngea. Foi realizada uma microcirugia para ressecção dos papilomas e um exame anatomopatológico do material da retirado da laringe. 0 histopatológico revelou presença de coilocitose, sendo esta alteração citopática sugestiva de infecção por H PV (Figura 3).

Cerca de 15 dias após a cirurgia, a paciente apresentou a primeira recidiva, com outras subseqüentes num período médio de dois meses, sendo então submetida à microcirurgia da laringe por três vezes e a laser de $\mathrm{CO}_{2}$ na última recidiva. N este ato operatório foi feita a ressecção completa dos papilomas. D estas peças cirúrgicas foi obtido DNA total usado na investigação molecular para detecção do genoma de H PV.

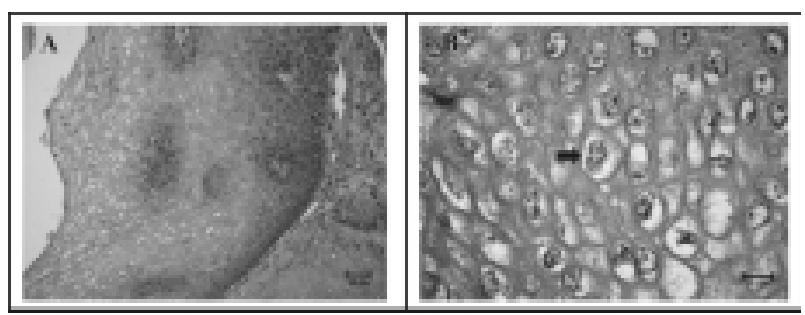

Figura 3: Histopatológico do tecido da laringe da paciente, corado por Hematoxilina-Eosina. (a) Em aumento de 400x. (b) A presença de coilocitose está indicada pela seta. 0 halo perinuclear é um efeito citopático sugestivo de infecção por HPV. Aumento de 1000x. 


\section{MATERIAIS E MÉTODOS}

A amostra foi proveniente da biópsia obtida por secção cirúrgica de pólipos da laringe. A extração do DNA foi realizada por maceração do tecido em nitrogênio líquido, com posterior utilização do kit de purificação do DNA genômico Wizard ${ }^{\circledR}$ (Promega Corporation, EUA), seguindo-se as instruções do fabricante.

O DNA purificado foi submetido a duas PCRs. $\mathrm{Na}$ primeira $P C R$, foram usados dois conjuntos de primers genéricos M Y09/11 e GP05/06 para a detecção de qualquer tipo de H PV. Posteriormente, na segundaPCR, foram utilizados os seguintes primers específicos para a genotipagem: H PV 6, 11, 16 e 18 (Tabela 2). Como controle positivo para os primers de H PV, foi utilizado D N A de células $\mathrm{H}$ ela, que contém inserido o genoma do H PV 18. Como controle da presença de DNA, foi usado um conjunto de primers que amplificam a região D $8 \mathrm{~S} 135$ do cromossomo 8.

0 protocolo determociclagem utilizado para as PCRs está descrito na Tabela 2. O s produtos de PCR foram submetidos à eletroforese em campo elétrico constante de $8 \mathrm{~V} / \mathrm{cm}$ em gel de poliacrilamida a $6 \%$, corado com brometo de etídio $(5 \mu \mathrm{g} / \mathrm{mL})$ e as imagens foram capturadas em sistema de vídeo documentação (I mageM asterVDS® , Amersham Pharmacia Biotech, EUA).

Tabela 2. Seqüências consenso dos primers utilizados e o tamanho esperado do fragmento amplificado, segundo Karlsen et al (1996).

\begin{tabular}{|c|c|c|c|}
\hline Tipos & $\mathrm{S}^{*}$ & Seqüências $5^{\prime} \rightarrow 3^{\prime}$ & $\begin{array}{l}\text { Fragmento } \\
(\mathrm{pb})\end{array}$ \\
\hline \multirow{2}{*}{ HPV 6} & $\mathrm{~F}$ & CAC GTC TGC AAC GAC CAT AG & \multirow{2}{*}{195} \\
\hline & $\mathrm{R}$ & CCA TGA AAT TCT AGG CAG CA & \\
\hline \multirow{2}{*}{ HPV 11} & $\mathrm{~F}$ & CGC AGA GAT ATA TGC ATA TGC & \multirow{2}{*}{90} \\
\hline & $R$ & AGT TCT AAG CAA CAG GCA CAC & \\
\hline \multirow{2}{*}{ HPV 16} & $\mathrm{~F}$ & TCA AAG CCA CTG TGT CCT GA & \multirow{2}{*}{119} \\
\hline & $\mathrm{R}$ & CGT GTT CTT GAT GAT CTG CAA & \\
\hline \multirow{2}{*}{ HPV 18} & $\mathrm{~F}$ & CCG AGC ACG ACA GGA ACG ACT & \multirow{2}{*}{172} \\
\hline & $\mathrm{R}$ & TCG TTT TCT TCC TCT GAG TCG CTT & \\
\hline \multirow{2}{*}{ D8S135 } & $\mathrm{F}$ & GGG AGG CTT TAT AAT TAT TTA GC & \multirow{2}{*}{100} \\
\hline & $\mathrm{R}$ & CTG GGC AAC AGA GTG GGA C & \\
\hline MY 09 & $R$ & CGT CCA AGA GGA TAC TGA TC & \multirow{2}{*}{450} \\
\hline MY 11 & $\mathrm{~F}$ & GCC CAG GGT CAT AAC AAT GG & \\
\hline GP 05 & $\mathrm{~F}$ & TTT GTT ACT GTG GTA GAT ACT AC & \multirow{2}{*}{170} \\
\hline GP 06 & $\mathrm{R}$ & GAA AAA TAA ACT GTA AAT CAT ATT C & \\
\hline
\end{tabular}

\section{RESULTADO}

0 histopatológico do material da biópsia resultou em observações de coilocitoses, alterações citopáticas sugestivas de infecção por H PV (Figura 3). A análise molecular resultou em bandas com os primers genéricos para amplificação de H PVs, indicando a presença do vírus (Figura 4a). A PCR com primers específicos para HPV do tipo 6, 11, 16 e 18, resultou na genotipagem de HPV do tipo 11 (Figura 4b).

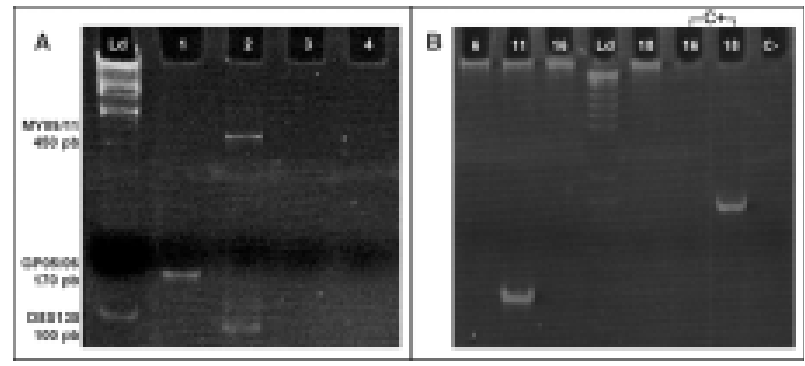

Figura 4: Gel de poliacrilamida a $6 \%$ com 0 resultado das amplificações: (a) PCR com primers genéricos. As amostras nas canaletas (1) com GP05/06 e (2) com MY09/11 e D8S135. As canaletas 3 e 4 são controles negativos para os conjuntos de primers citados, respectivamente. (b) PCR com primers específicos para HPV 6, 11, 16 e 18, mostrando amplificação na canaleta do HPV11. Células HeLa foram usadas como controle positivo com os primers para HPV 16 e 18. Ld: Marcador de tamanho de $100 \mathrm{pb}$.

\section{DISCUSSÃO}

A papilomatose laríngea juvenil é uma doença que acomete crianças e provoca alterações respiratórias graves que se caracterizam por quadros de dispnéia e obstrução glótica, levando o paciente a tratamentos cirúrgicos de urgência, às vezes com traqueostomias que deixam seqüelas definitivas nestas crianças.

A pesar da papilomatose laríngea recorrente de início juvenil ser uma neoplasia de comportamento histológico benigno, esta doença apresenta recidivas freqüentes. Pelo menos a metade das crianças acometidas necessita de mais de 10 internações para extrair definitivamente os papilomas, e aproximadamente $7 \%$ necessitam de cerca de 100 internações. Por isso, a papilomatose laríngea é uma enfermidade cujo tratamento se revela, muitas vezes, pouco eficaz, gerando frustração tanto para o corpo clínico quanto para o paciente. ${ }^{32}$

A caracterização do genótipo viral associado à papilomatose recorrente de laringe nas crianças é importante, uma vez que o tipo viral podeestar associado ao desenvolvimento tumoral nestes pacientes. $G 0$ et $a^{36}$ relatam que de sete crianças tratadas de papilomatose laríngea, quatro delas desenvolveram carcinoma espinocelular da laringe 28 anos após o tratamento, sendo genotipados os H PV 6 e 11. O s mesmos autores concluíram que a transição de papiloma para carcinoma nestes pacientes não passou pela fase de progressão presente no modelo da carcinogênese, já que estes tumores são muito difíceis de serem diagnosticados 
precocemente. $\mathrm{N}$ esse contexto, a papilomatose laríngea pode ser considerada como outro fator de risco para o câncer da laringe. Rady et al ${ }^{37}$ mencionaram o papel do H PV 11 e mutação de p53 na transformação maligna do epitélio através de instabilidade genética progressiva. Estes autores identificaram que a mutação em p53 está associada à integração do H PV 11 em lesões histologicamente malignas. Rabah et al ${ }^{38}$ afirmam que 0 H PV 11 está associado com a forma mais agressiva de papilomatose recorrente. $0 \mathrm{~s}$ autores avaliaram 61 pacientes e concluíram que a determinação do tipo viral era um fator importante no prognóstico das crianças. $\mathrm{N}$ aquele estudo, o H PV 11 foi o tipo viral mais comum entre crianças afro-americanas, com diagnóstico em idade mais jovem (três anos), o curso da doença apresentou-se mais ativo e agressivo, com longos períodos de recidiva. Do grupo acompanhado, 5\% (3/ 61) desenvolveram papilomatose invasiva e evoluíram para carcinoma broncogênico, concluindo-se que 0 genótipo do H PV confere um caráter agressivo à papilomatose laríngea.

O histopatológico da biópsia da laringe indicou a presença de halos perinucleares, denominados coilocitoses. Este achado é sugestivo da infecção por H PV, uma vez que se trata de um efeito citopático causado por este vírus em particular. A análise molecular do mesmo material com os primers inespecíficos, M Y09/11 e GP05/06 para a amplificação de qualquer tipo deH PV veio corroborar o achado do histopatológico. A utilização de dois conjuntos de primers genéricos para a detecção inicial do H PV se justifica pela necessidade de aumentar a capacidade de detecção do genoma viral por PCR, uma vez que a inserção do genoma viral no genoma da célula ocorre com perda parcial de seqüências dos genes do H PV, com perda das regiões de anelamento dos primers genéricos.

O conjunto de primers M Y09/11 é largamente utilizado em estudos epidemiológicos das Américas do N orte e Sul eÁsia, já o conjunto GP05/06 é mais usado na Europa. A pesar do conjunto M Y09/11 se apresentar mais sensível que o conjunto GP05/06, a utilização de ambos no presente estudo para a triagem inicial se justifica pela necessidade de aumentar a eficiência da detecção do genoma viral por PCR. Um estudo comparativo entre os dois conjuntos, utilizando vários tipos de HPVs, demonstrou que apesar dos primers M Y09/11 se mostrarem mais robustos, apresentaram relativa ineficiência na detecção do H PV 35, enquanto os primers G P05/06 apresentaram falhas para os H PVs 53 e 61.39

A análise molecular do tipo viral foi realizada com primers específicos para os H PV s 6, 11, 16 e 18, e resultou na genotipagem do H PV do tipo 11 . 0 H PV 11 é considerado um tipo viral de baixo risco oncogênico, e isso talvez explique o fato da paciente apresentar pólipos recorrentes na laringe e não um carcinoma espinocelular. Estudos recentes demonstram que, apesar da proteína E6 de H PV 11 ser capaz de degradar a p53 via ubiquitinação, a sua eficiência não se compara a das oncoproteínas E6 dos H PVs de alto risco. ${ }^{40,41}$

A papilomatose laríngea tem característica recorrente após a remoção cirúrgica de papilomas porque genomas de HPV são mantidos nas células da camada basal do epitélio da laringe. 0 vírus, nessa camada, apresenta um ciclo de vida latente, não produzindo proteínas do capsídeo e, conseqüentemente, não originando outros vírus. Esta estratégia garante a manutenção da infecção nas células basais e, conseqüentemente a formação de pólipos subseqüente a cirurgias. ${ }^{9} \mathrm{~A}$ erradicação total da capacidade de formação de novos papilomas só irá ocorrer quando a peça cirúrgica se testar negativa para o genoma de H PV.

A pesar da literatura relatar que os papilomas laríngeos apresentam progressão lenta, ${ }^{32}$ o presente relato de caso demonstrou o oposto, pois o tempo médio de recorrência dos pólipos, que acometeram a paciente, foi de dois meses.

A confirmação da presença do H PV do tipo 11 corrobora os achados descritos na literatura, que associam esse H PV aos papilomas laríngeos recorrentes de início juvenil. Adicionalmente, a genotipagem confirma os achados de outros autores que argumentam que a ocorrência latente do H PV 11 tem participação na evolução dessa patologia em crianças. ${ }^{9,10,32}$

Portanto, a genotipagem do H PV em crianças com papilomatose recorrente da laringe e a condição de portadoras de condilomatose ou HPV em suas mães é uma forma segura de se conhecer e adotar a terapia específica para o tratamento de ambos. Assim, seria pertinente na clínica de ginecologia e obstetrícia testar amostras da mucosa da vulva, canal vaginal e cérvice por PCR para a detecção do genoma do H PV. N os casos positivos, a cesariana seria o método de escolha para a parturiente, reduzindo a ocorrência de infecção no neonato.

\section{REFERÊNCIAS BIBUOGRÁFICAS}

1. Jacob SE, SreevidyaS, Chacko E, Pillai M R. C ellular manifestations of human papillomavirusinfection in laryngeal tissues. J Surg O ncol 2002;79:142-50.

2. $M$ ünger $K$, Basile JR, D uensing $S$, Eichten $A$, Gonzalez $\mathrm{SL}, \mathrm{G}$ raceM , et al. Biological activities and molecular targets of the human papillomavirus E7 oncoprotein. 
Oncogene 2001;20:7888-98.

3. Butel JS. Viral carcinogenesis: revelation of molecular mechanismsand etiology of human disease. $C$ arcionogenesis 2000;21(3):405-26.

4. M atzow T, Boysen $M$, K alantari $M$, Johansson $B, H$ agmar B. Low detection rate of H PV in oral and laryngeal carcinomas. Acta O ncol 1998;37(1):73-6.

5. Lin KY, WestraWH , KashimaH K, M ountsP. Coinfection of hpv-11 and hpv-16 in a case of laryngeal squamous papillomas with severe dysplasia. Laryngoscope 1997;107:942-7.

6. Rivoire WA, Capp E, Corleta HE, Silva ISB. Bases biomoleculares da oncogênesecervical. Rev Bras $C$ ancerol 2001;47(2):179-84.

7. N oronhaV, M ello W, VillaL, Brito A, M acêdo R, Bisi F, et al. Papilomavírus humano associado a lesões de cérvice uterina. Rev Soc Bras M ed Trop 1999;32(3):235-40.

8. Villa LL. Aspectos moleculares da oncogênese por papilomavírus. In: Bibbo M, Silva Filho M AS, editores. Lesõesrelacionadasà infecção por H PV no trato anogenital. Rio deJ aneiro: Revinter; 1998. p. 51-7.

9. Stubenrauch F, LaiminsLA. H uman papillomaviruslifecycle: activeand latent phases. Cancer Biol 1999;9:379-86.

10. Aaltonen LM, Rihkanen $H$, Vaheri A. Human papillomavirusin larynx. Laryngoscope 2002;112:700-7.

11. Stevens LM. Papillomavirus. J Am Med Assoc 2002;287(18):2452.

12. Picconi M A, Eiján AM , D istéfano AL, Pueyo S, Alonio LV, TeyssiéAR, et al. H uman papillomavirus (H PV) D N A in penilecarcinomas in Argentina: analysis of primary tumors and lymph nodes. J M ed Virol 2000;61:65-9.

13. Badaracco G, Venuti A, M orello R, M uller A, M arcante M L. H uman papillomavirus in head and neck carcinomas: prevalence, physical and relationship with clinical/pathological parameters. Anticancer Res 2000;20:1301-6.

14. N iv A, Sion-Vardi N, Gatot A, N ash M , Fliss D M . Identification and typing of human papillomavirus (HPV) in squamous cell carcinoma of the oral cavity and oropharynx. J Laryngol 0 tol 2000;114:41-6.

15. Smith EM, Summersgill KF, Allen J, H offman HT, M cCulloch T, Turek LP, et al. H uman papillomavirus and risk of laryngeal cancer. Ann $\mathrm{O}$ tol Rhinol Laryngol 2000;109:1069-76.

16. van $H$ outen VM M , van den Brekel M W M , Denkers $F$, Colnot DR, WestergaJ, van D iest PJ, et al. M olecular diagnosis of head and neck cancer. Recent Results $C$ ancer Res 2000;157:90-106.

17. Rowley H . M olecular biology series: themolecular genetics of head and neck cancer.J L aryngol 0 tol 1998;112:607-12.

18. Paz IB, Cook N , O dom-M aryon T, XieY, W ilczynski SP. H uman papillomavirus (H PV) in head and neck cancer: an association of H PV 16 with squamouscell carcinoma of
Waldeyer's tonsillar ring. C ancer 1997;79(3):595-604.

19. Thompson LD . D iagnostically challenging lesion in head and neck pathology. Eur Arch Otorhinolaryngol 1997;254(8):357-66.

20. G onzalez-G omezP, Bello M J, Alonso M E, ArjonaD , Lomas J, deCamposJM , et al. CpG island methylation status and mutation analysis of the RB1 geneessential promoter re gion and protein-binding pocket domain in nervous system tumours. Br J Cancer 2003;88:109-14.

21. M ünger K. C lefts, grooves, and (small) pockets: thestructure of the retionoblastoma tumor suppressor in complex with its cellular target $E 2 F$ unveiled. PNAS 2003;100(5):2165-7.

22. Xiao B, Spencer J, Clements A, Aki-Khan N , M ittnacht S, Broceño $C$, et al. C rystal structure of the retinoblastoma tumor suppressor protein bound to E2F and the molecular basis of its regulation. PN AS 2003;100(5):2363-8.

23. Classon M , H arlow E. Theretinoblastomatumour suppressor in development and cancer. N at Rev 2002;2:910-7.

24. Sandal T. M olecular aspects of the mammalian cell cycle and cancer. O ncologist 2002;7:73-81.

25. Saunders J R Jr. Thegenetic basic of head and neck carcinoma. Am J Surg 1997;174:459-61.

26. G leich LL, SalamoneFN. M olecular genetics of head and neck cancer. C ancer C ontrol 2002;9(5):369-78.

27. Lewin B. O ncogenes e câncer. In: G enesVII. São Paulo: Artmed; 2000. p. 837-73.

28. Kehmeier E, Rühl H, Voland B, Stöppler M C , Androphy E, Stöppler H . C ellular steady-state levels of "high risk" but not "low risk" human papillomavirus (H PV) E6 proteins are increased by inhibition of proteasome dependent degradation independent of their p53- and E6AP-binding capabilities. Virology 2002;299:72-87.

29. Vogel F, M otulsky AG . M utação: mutação somática, câncer e envelhecimento. In: genética humana: problemas e abordagens. 3a ed. Rio de Janeiro: G uanabara Koogan; 2000. p. 355-76.

30. GriffithsAJF, M iller JH, Suzuki DT, Lewontin RC, G elbart W M. Genética e diferenciação celular. In: Introdução à genética. 6a ed. Rio deJ aneiro: Guanabara Koogan; 1998. p. 682-708.

31. Vousden K. Interactions of human papillomavirustransforming proteins with the products of tumor suppressor genes. FASEB J 1993;7:872-9.

32. Conejo PR, Puerto M JM , Soto AM , M artinez AM , Sanz M AV. Papilomatosis respiratoria recurrente: una causa de dificultad respiratoria progresiva. An Esp Pediatr 2001;55(6):558-60.

33. Vancuroval, Wu R, M iskolci V, Sun S. Increased p50/p50 N F-kB activation in human papillomavirus type 6 - or type 11-induced laryngeal papilloma tissue. J Virol 2002;76(3):1533-6. 
34. Auborn KJ, Little RD, Platt THK, Vaccariello MA, Schildkraut CL. Replicative intermediates of human papillomavirustype 11 in laryngeal papillomas: site of replication initiation and direction of replication. Cell Biol 1994;91:7340-4.

35. Karlsen $F$, Kalantari $M$, Jenkins A, Pettersen $E$, K ristensen $G, H$ olm R, et al. U se of multiple PCR primer sets for optimal detection of human papillomavirus. J Clin Microbiol 1996;34(9):2095-100.

36. Go C, Schwartz M R, D onovan DT. M olecular transformation of recurrent respiratory papillomatosis: viral typing and p53 overexpression. Ann 0 tol Rhinol Laryngol 2003;112(4):298-302.

37. Rady PL, Schnadig VJ, Weiss RL, H ughesTK, Tyring SK . $M$ alignant transformation of recurrent respiratory papillomatosis associated with integrated human papillomavirus type $11 \mathrm{DNA}$ and mutation of p53. Laryngoscope 1998:108(5):735-40.
38. Rabah R, Lancaster WD , T homas R, GregoireL. H uman papillomavirus-11-associated recurrent respiratory papillomatosisismoreaggressivethan human papillomavirus6-associated disease. Pediatr D ev Pathol 2001:4(1):68-72.

39. Q u W, Jiang G, CruzY, Chang CJ, H o GYF, K lein RS, et al. $P C R$ detection of human papillomavirus: comparison between M Y 09/M Y 11 and G P05+/G P 06+primer systems. J Clin M icrobiol 1997;35(6):1304-10.

40. Souvinos G, RizosE, SpandidosD A. p53 codon 72 polymorphism is linked to the development and not the progression of benign and malignant laryngeal tumours. 0 ral O ncol 2001;37:572-8.

41. Storey A, Thomas M , Kalita A, H arwood C, G ardiol D, $M$ antovani $F$, et al. Role of a p53 polymorphism in the development of human papillomavirus-associated cancer. N ature 1998;393:229-34. 